\title{
Correction
}

\section{Correction: Karimi, P., et al. Crocetin Prevents RPE Cells from Oxidative Stress through Protection of Cellular Metabolic Function and Activation of ERK1/2. Int. J. Mol. Sci. 2020, 21, 2949}

\author{
Padideh Karimi ${ }^{1}$, Ali Gheisari ${ }^{2}$, Sylvia J. Gasparini ${ }^{1}$, Hossein Baharvand ${ }^{3,4}$, Faezeh Shekari ${ }^{3,4}{ }^{\mathbb{D}}$, \\ Leila Satarian ${ }^{5, *}$ and Marius Ader ${ }^{1, *(1)}$
}

1 CRTD/Center for Regenerative Therapies Dresden, Center for Molecular and Cellular Bioengineering, Technische Universität Dresden, 01307 Dresden, Germany; padideh.karimi_sejzei@mailbox.tu-dresden.de (P.K.); Sylvia.gasparini@tu-dresden.de (S.J.G.)

$2 \mathrm{CMCB} /$ Center for Molecular and Cellular Bioengineering, Technische Universität Dresden, 01307 Dresden, Germany; ali.gheisari@tu-dresden.de

3 Department of Stem Cell and Developmental Biology, Cell Science Research Center, Royan Institute for Stem Cell Biology and Technology, ACECR, Tehran 1665659911, Iran; baharvand@royaninstitute.org (H.B.); faezehshekari@gmail.com (F.S.)

4 Department of Developmental Biology, University of Science and Culture, Tehran 1665659911, Iran

5 Department of Brain and Cognitive Science, Cell Science Research Center, Royan Institute for Stem Cell Biology and Technology, ACECR, Tehran 1665659911, Iran

* Correspondence: leilasatarian@royaninstitute.org (L.S.); marius.ader@tu-dresden.de (M.A.)

check for updates

Citation: Karimi, P.; Gheisari, A.; Gasparini, S.J.; Baharvand, H.;

Shekari, F.; Satarian, L.; Ader, M.

Correction: Karimi, P., et al. Crocetin Prevents RPE Cells from Oxidative Stress through Protection of Cellular Metabolic Function and Activation of ERK1/2. Int. J. Mol. Sci. 2020,

21, 2949. Int. J. Mol. Sci. 2021, 22, 244. https://doi.org/10.3390/ijms22010244

Received: 23 November 2020 Accepted: 26 November 2020 Published: 29 December 2020

Publisher's Note: MDPI stays neutral with regard to jurisdictional claims in published maps and institutional affiliations.

Copyright: (C) 2020 by the authors. Licensee MDPI, Basel, Switzerland. This article is an open access article distributed under the terms and conditions of the Creative Commons Attribution (CC BY) license (https: / / creativecommons.org/ licenses/by/4.0/).
The authors wish to make the following correction to Figure $6 \mathrm{~B}$ of this article [1]: the merge image of group "Pre 15min" (row 5, column 3) was also added by mistake as the merge image of group "TBHP only 15min" (row 3, column 3). The images of the DAPI and pERK $1 / 2$ single channels are correct for all experimental groups. The correct merge image has been added for "TBHP only 15min" (row 3, column 3) (Figure 1).

A

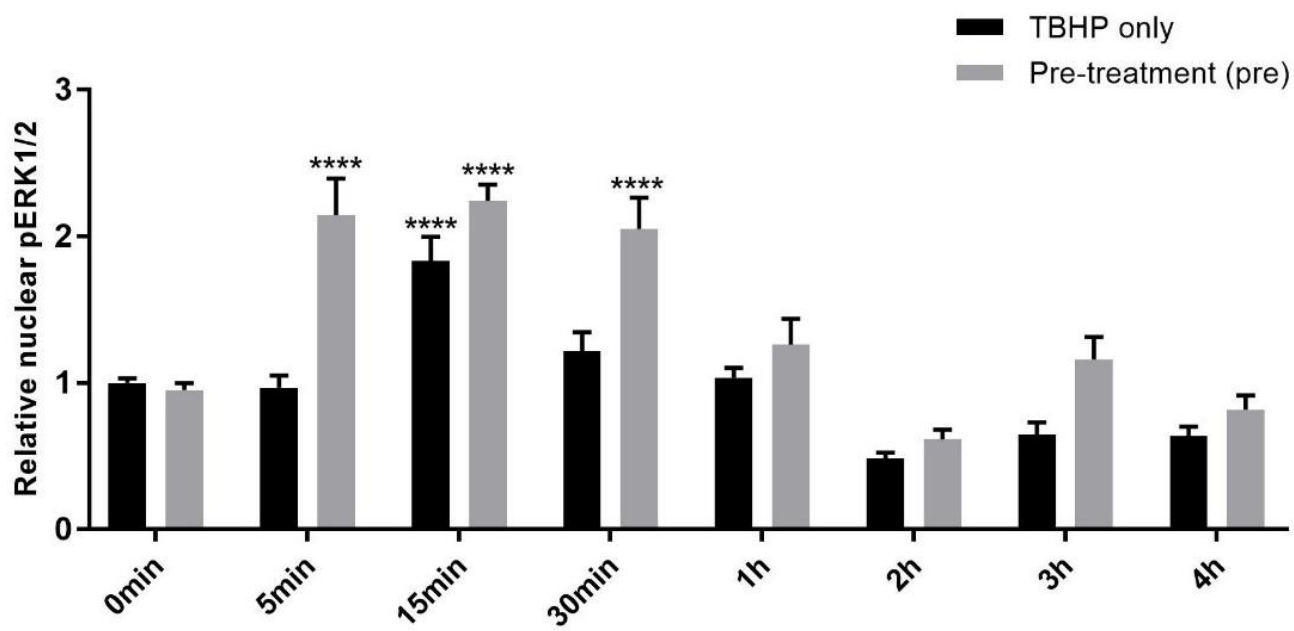

Figure 1. Cont. 


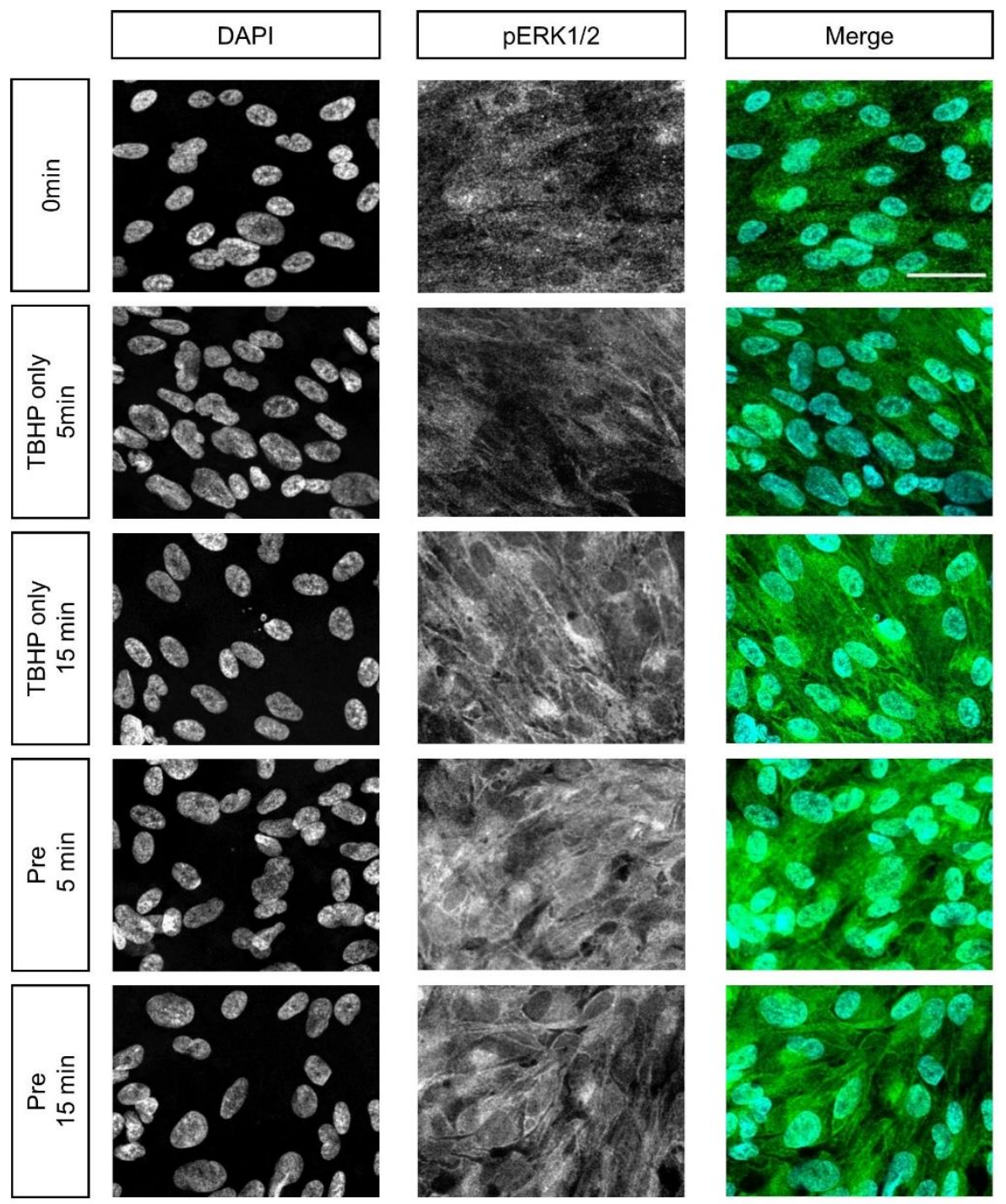

Figure 1. Effect of crocetin on extracellular signal-regulated kinase $1 / 2($ ERK1/2) activation in ARPE19 cells. ERK1/2 phosphorylation was investigated at different time points $(5,15,30 \mathrm{~min}$ and 1, 2, 3, $4 \mathrm{~h})$ during $4 \mathrm{~h}$ exposure to TBHP. ARPE19 cells were only exposed to TBHP or were additionally pretreated for $24 \mathrm{~h}$ with crocetin. While ERK1/2 showed activation and nuclear translocation in the TBHP only group at $15 \mathrm{~min}$, ERK1/2 activation was observed in the pre-treatment group already at $5 \mathrm{~min}$ and lasted for $30 \mathrm{~min}$ (A). At 5, 15, and $30 \mathrm{~min}$ intervals, the activation level of ERK1/2 in the pre-treatment group was significantly and constantly higher than in the TBHP-only group (A). Thus, pre-treatment with crocetin caused activation of ERK1/2 earlier and for a longer time in comparison to TBHP-only. Immunocytochemistry results (B) on ARPE19 cells in controls (0 min), TBHP-only at $5 \mathrm{~min}$, TBHP-only at $15 \mathrm{~min}$, as well as TBHP plus crocetin pre-treatment at 5 and $15 \mathrm{~min}$ are shown for DAPI, and phosphorylated (p) ERK1/2; the third column represents the merged images of DAPI and pERK1/2. An increase in pERK1/2 signal was observed at $15 \mathrm{~min}$ but not at $5 \mathrm{~min}$ in TBHP-exposed cells (in comparison to non-exposed (0 $\mathrm{min}$ ) controls), but already at $5 \mathrm{~min}$ and also at $15 \mathrm{~min}$ in TBHP-exposed cells pre-treated with crocetin. Scale bar: $40 \mu \mathrm{M}$. Data are shown as mean \pm S.E.M, p-value: $<0.0001{ }^{(* * * *)}$ (one-way ANOVA, Dunnett's multiple comparison test).

The authors would like to apologize for any inconvenience caused to the readers by this change.

Conflicts of Interest: The authors declare no conflict of interest. 


\section{Reference}

1. Karimi, P.; Gheisari, A.; Gasparini, S.J.; Baharvand, H.; Shekari, F.; Satarian, L.; Ader, M. Crocetin Prevents RPE Cells from Oxidative Stress through Protection of Cellular Metabolic Function and Activation of ERK1/2. Int. J. Mol. Sci. 2020, $21,2949$. [CrossRef] [PubMed] 